\section{Michigan Technological 1 8 8 5 University}

Michigan Technological University Digital Commons @ Michigan Tech

Dec 1st, 12:00 AM

\title{
Conference Proceedings for The 2nd Global Virtual Conference of the Youth Environmental Alliance in Higher Education
}

Youth Environmental Alliance in Higher Education

Follow this and additional works at: https://digitalcommons.mtu.edu/yeah-conference

\section{Recommended Citation}

Youth Environmental Alliance in Higher Education, "Conference Proceedings for The 2nd Global Virtual Conference of the Youth Environmental Alliance in Higher Education" (2020). Global Conference of the Youth Environmental Alliance in Higher Education. 49.

10.37099/mtu.dc.yeah-conference/2020/all-events/49 


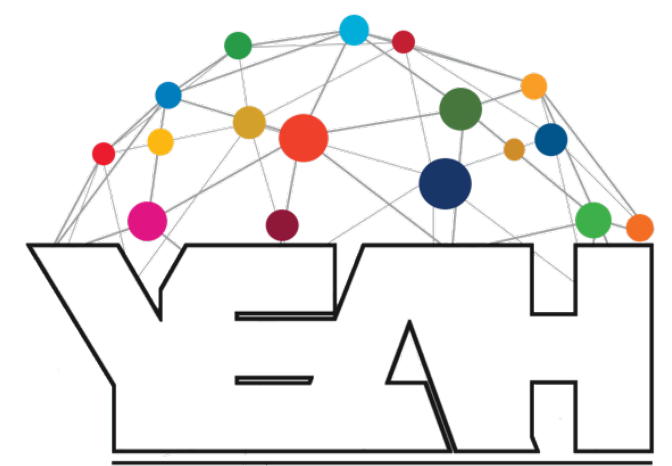

Youth Environmental Alliance in Higher Education

\section{CONFERENCE PROCEEDINGS}

The $2^{\text {nd }}$ Global Virtual Conference Youth Environmental Alliance in Higher Education

December 09, 2020 
The Youth Environmental Alliance in Higher Education (YEAH) is a transdisciplinary, multi-institutional network that equips students with real-world experience of collaborative, evidence-based approaches to global environmental sustainability. In today's students, we see agents of change for the future. Therefore, the YEAH Network connects institutions of higher education from all over the globe to provide integrated knowledge to students that empowers them to address complex global environmental problems.

The YEAH Network develops virtual classrooms at the undergraduate and graduate levels that provide environmental learning through structured and real-life experiences of international negotiations. Students and seasoned investigators from diverse backgrounds collaborate for a common purpose giving them a sense of belonging, purposefulness, and continued motivation to achieve global goals. Students are introduced into the realms of policy and trained to engage actively in international collaborations that are tackling global environmental issues. 


\section{(36) Colorado State University \\ Colorado State \\ University \\ Fort Collins, CO, United \\ States \\ $\underline{\text { DERBY }}$}

university oI verpy

England, United Kingdom

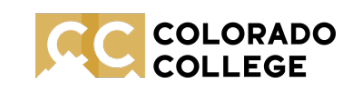

Colorado College

Colorado Springs, CO, United States

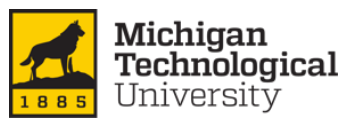

Michigan Technological

University

Houghton MI, United

States

\author{
3 \\ VANDERBILT \\ UNIVERSITY \\ Vanderbilt University \\ Nashville, TN, United \\ States

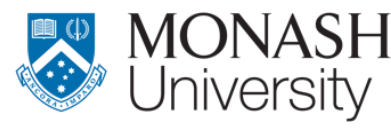

Monash University

Melbourne, Australia

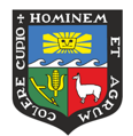

Universidad Nacional

Agraria

La Molina, Peru

MORAVIAN

COLLEGE

Moravian College

Bethlehem, PA, United

States
UCDNN | UNIVERSITYOF

University of Connecticut

Storrs, CT, United States

\section{BOSTON}

UNIVERSITY

Boston University

Boston, MA, United States

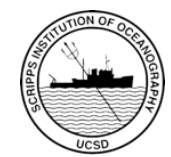

Scripps Institute of

Oceanography

San Diego, CA, United States

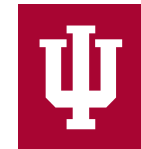

Indiana University Bloomington, IN, United States 
This page is intentionally left blank. 
The $2^{\text {nd }}$ Global Virtual Conference of the Youth Environmental Alliance in Higher

Education

\section{Conference Proceedings}
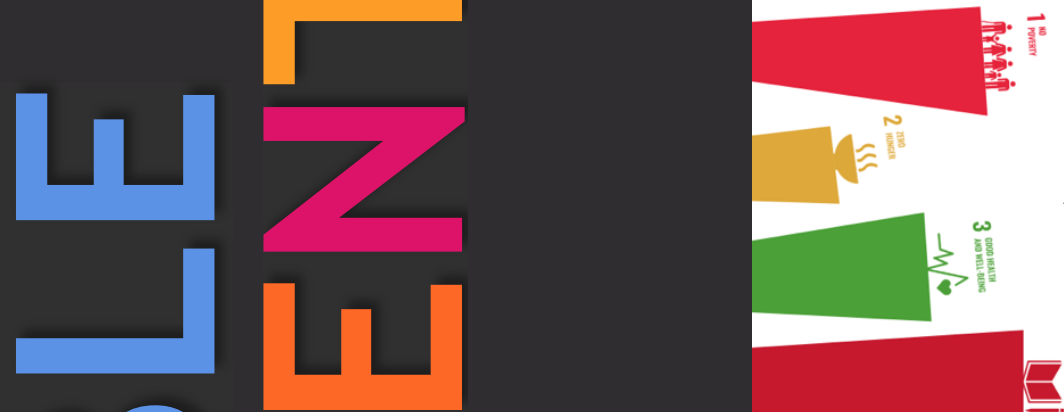

Compiled by YEAH Fellows Amna Ijaz and Emma Conrad-Rooney

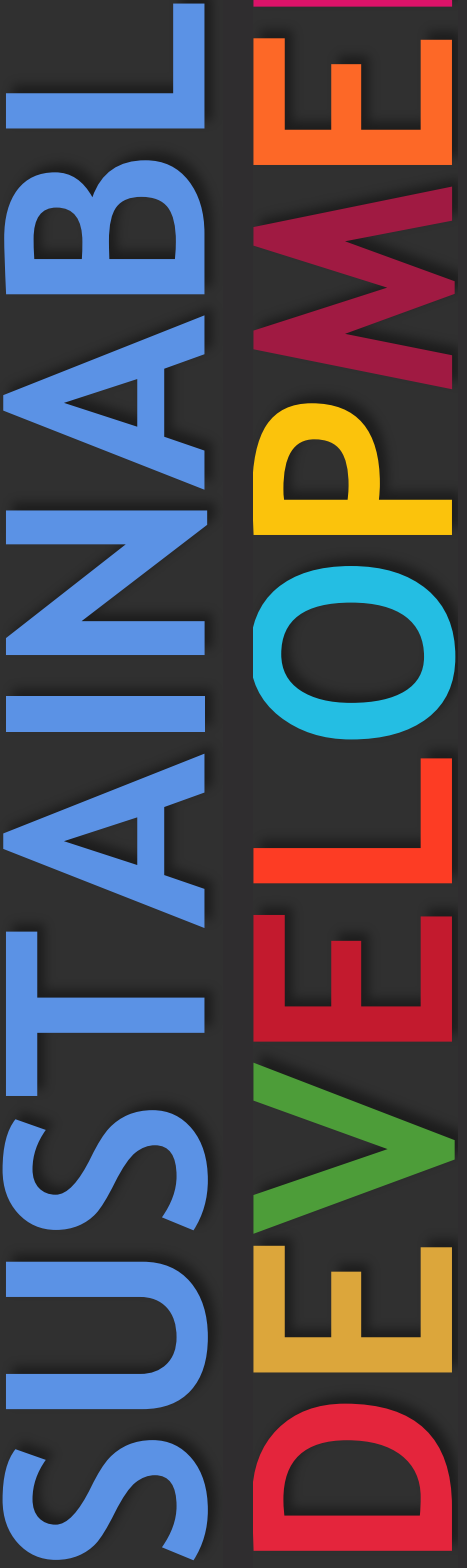

\section{(c) creative}

This work is licensed under CC BY-NC-ND 4.0 https://creativecommons.org/licenses/by-nc-nd/4.0/?ref=chooser-v1 
This page is intentionally left blank. 


\section{Table of Contents}

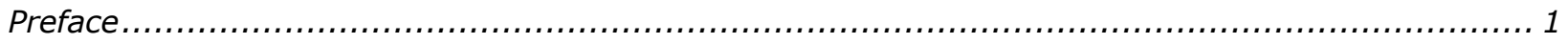

Session 1A. Zero Hunger and Good Health \& Wellbeing (SDGs 2, 3, 4, 6) ............................. 3

Sustainable Development Goal 3: Mental Health and Well-Being ................................. 4

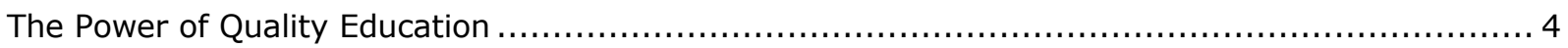

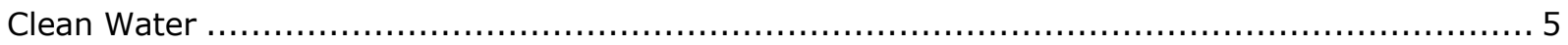

SDG 2 - Zero Hunger; Case Study: UN World Food Programme (WFP) ............................. 5

Oaxaca \& Climate Change: Preserving the Environment \& Indigenous, Medicinal Knowledge.......... 6

Session 1B. Affordable \& Clean Energy and Industry, Innovation \& Infrastructure (SDGs 7, 9) ......... 7

The United States' Renewable Energy Utilization............................................... 8

Internet Expansion Plan Proposal in Developing Countries: Peru as a Case Study $\ldots \ldots \ldots \ldots \ldots \ldots \ldots . \ldots$

Glitter in make up as microplastics: comparative life cycle analysis of biodegradable and plastic

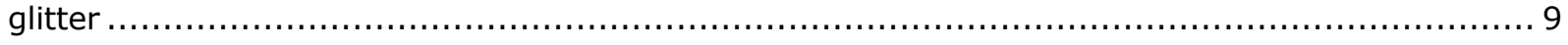

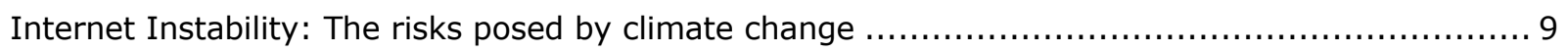

Session 1C. Reduced Inequalities and Gender Equality (SDGs 2, 5, 10) .............................. 10

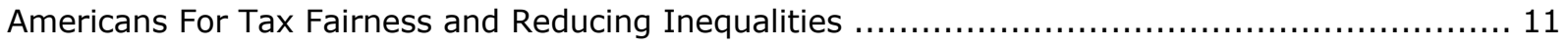

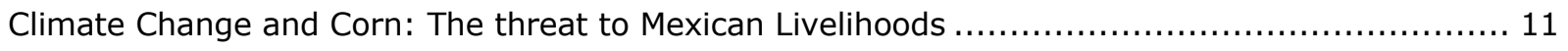

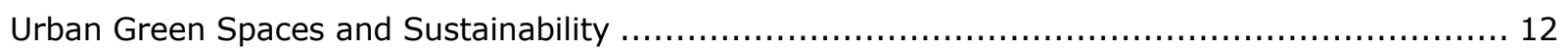

The Intersectionality of Environmental and Societal Well-Being in Reducing Inequalities ............ 12

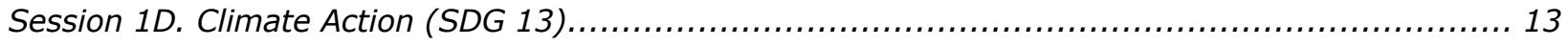

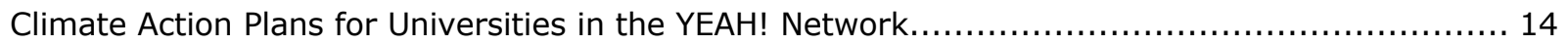

Traditional Ecological Knowledge and Environmental Policy in Southeast Alaska ...................... 14

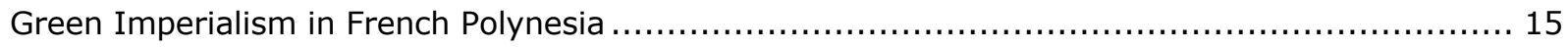

Preparing for the Inevitable Low-Carbon Economy: Current Actions of the United States of America,

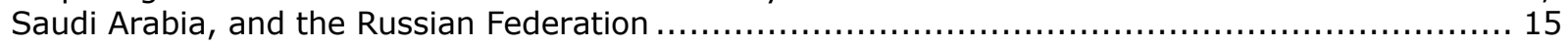

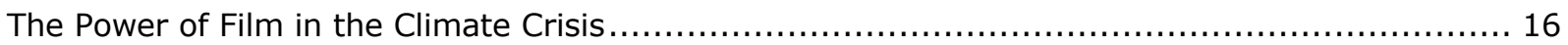

Session 1E. Peace, Justice, \& Strong Institutions and Partnerships for the Goals (SDGs 13, 16, 17) . 17

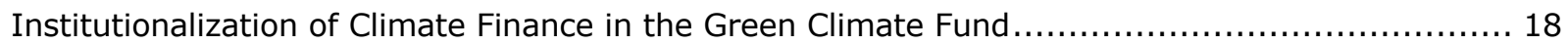

Disparate Impacts of Climate Change on Indigenous Communities in the Arctic Region .............. 18

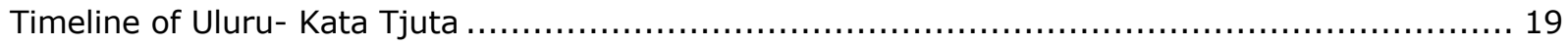

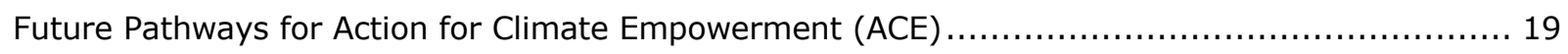

Police Brutality and State Violence: A Global Phenomenon ........................................ 20

Session 2A. Interdisciplinary SDG topics (SDG nexus spaces) ...................................... 21

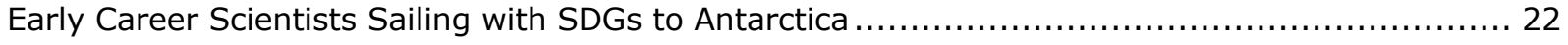

The Kankyo Café method of environmental dialogue and SDGs ................................... 22

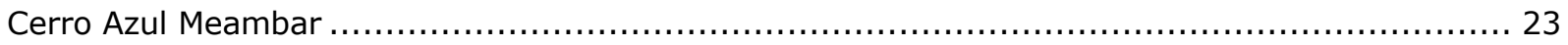


Talanoa Dialogues on the SDGs.....

The Effects of Palm Oil on the Habitats, Biodiversity, and Environment of Populations in Indonesia and Southeast Asia.....

Session 2B. Industry, Innovation \& Infrastructure and Sustainable Cities \& Communities (SDGs 9, 11)

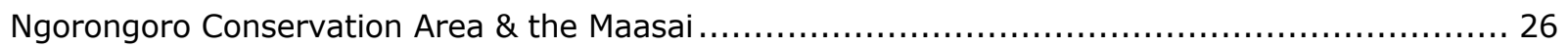

The Influence of Urban Planning on Sustainable Lifestyles....................................... 26

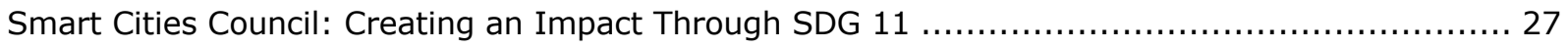

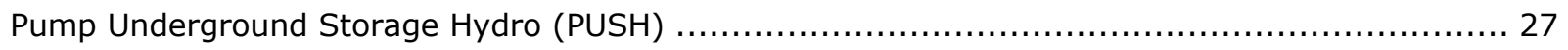

Community Participation and Sustainable Livelihoods: A Case Study of Hiware Bazar (India) ....... 28

Session 2C. Responsible Consumption and Production (SDG 12) ................................... 29

The Relationship Between Producer Transparency and Sustainable Consumption.................... 30

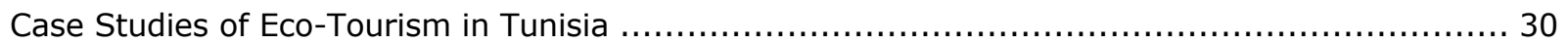

A Comparative Analysis of China and Indonesia's Adaptation Techniques for Rice Production ....... 31

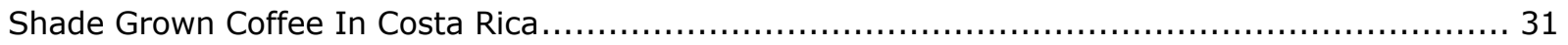

Agrivoltaics: Exploring the Opportunities \& Barriers to Combined Solar and Agriculture Systems .. 32

Session 2D. Climate Action and Good Health \& Wellbeing (SDGs 3, 13) ............................... 33

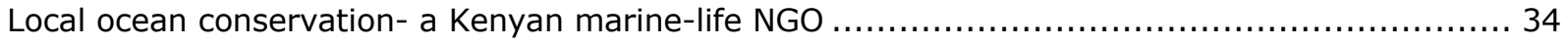

Climate Change and Jamaican Agriculture: Addressing Impacts on Small-Scale Farmers ............ 34

Hauscarán National Park: Chavin Culture Through the Lens of Traditional Artwork .................. 35

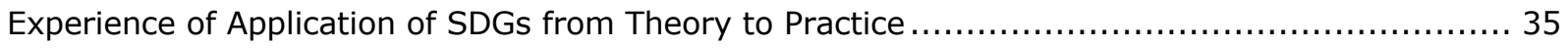

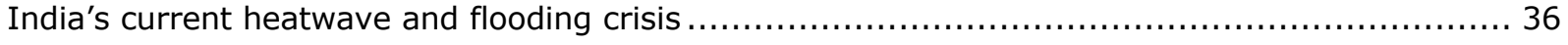

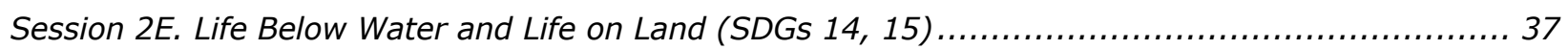

Effects of Deforestation on Marine Ecosystems and Biodiversity: Case Studies from the United

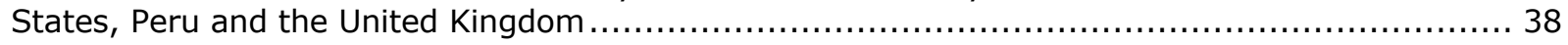

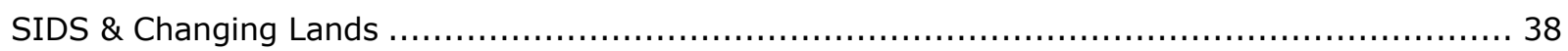

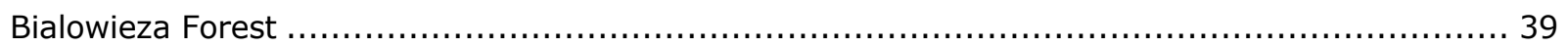

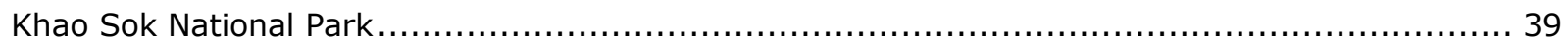

Arenal Volcano National Park in Costa Rica ....................................................... 40 


\section{Preface}

The present compilation contains abstracts of research projects presented at the $2^{\text {nd }}$ Global Virtual Conference of the Youth Environmental Alliance in Higher Education held on Wednesday, December 09, 2020. The theme of the conference was SDGS for the SDGs: Students Doing Goal-Oriented Science for the Sustainable Development Goals. The aim of the Conference was to provide a platform to students, researchers, and educators from all across the globe to share their knowledge and practical efforts toward implementation of the 17 Sustainable Development Goals (https://sdgs.un.org/goals).

The YEAH Global Virtual Conference proudly hosted 201 registrants and showcased 47 student research projects from 5 continents as listed below.

\begin{tabular}{llc}
\hline \multicolumn{1}{c}{ Universities } & \multicolumn{1}{c}{ Country } & Number of abstracts \\
Indiana University & United States & 19 \\
Colorado State University & United States & 8 \\
Boston University & United States & 6 \\
Michigan Technological University & United States & 4 \\
Colorado College & United States & 2 \\
Massey University & New Zealand & 2 \\
Ecoles Normales Supérieures & France & 1 \\
Kyushu University & Japan & 1 \\
Monash University & Australia & 1 \\
Moravian College & United States & 1 \\
Scripps Institute of Oceanography & United States & 1 \\
Wageningen University & The Netherlands & 1 \\
& & 47 \\
\hline
\end{tabular}

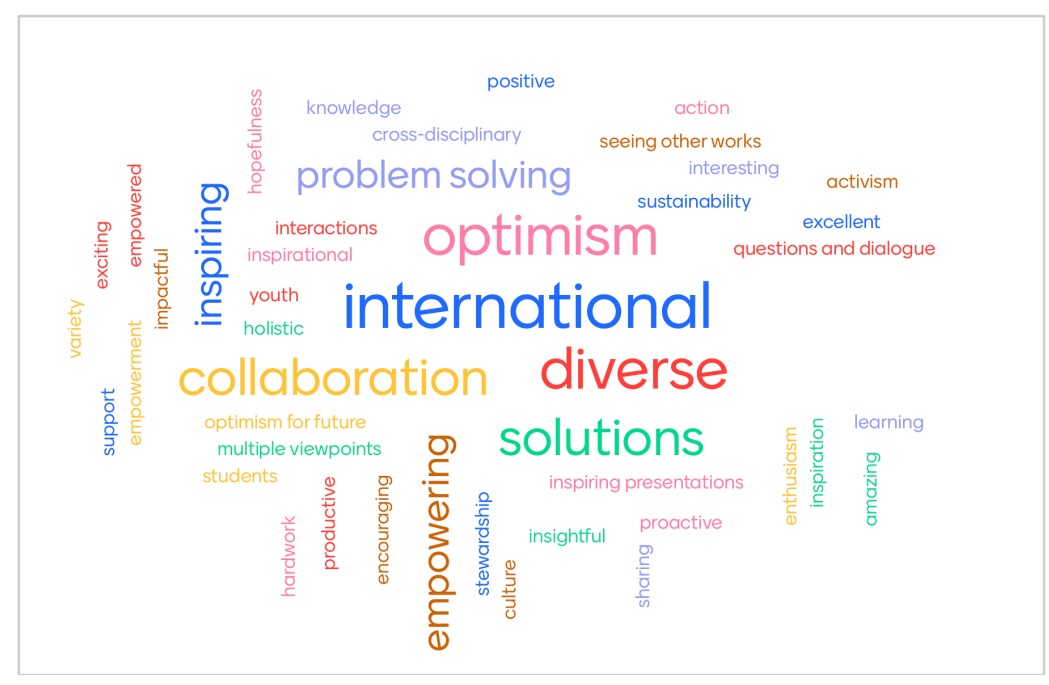

Participant response to Mentimeter question: "What are the three highlights from your conference experience" 
This page is intentionally left blank. 


\section{Session 1A. Zero Hunger and Good Health \& Wellbeing (SDGs 2, 3, 4, 6)}
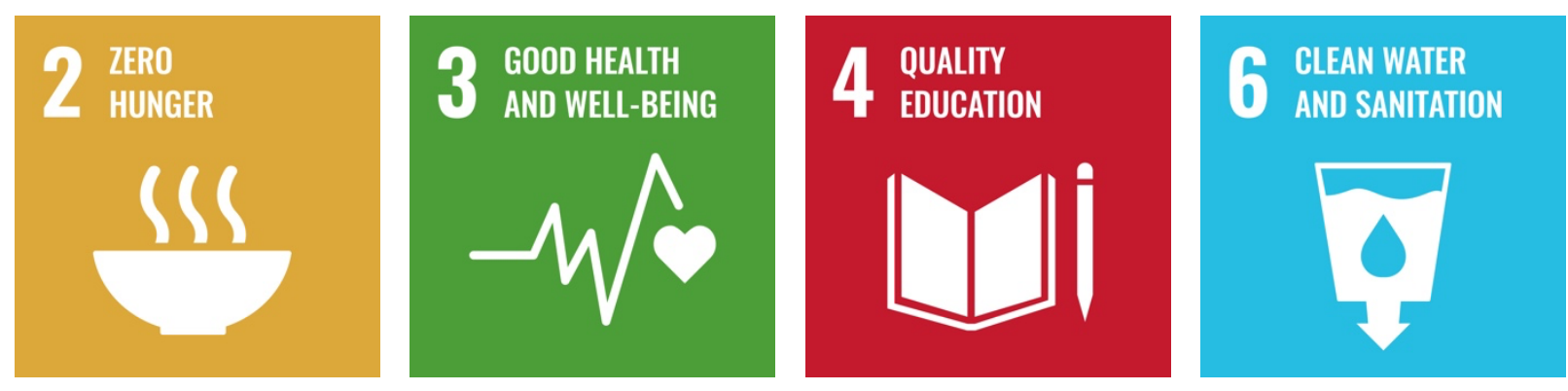


\title{
Sustainable Development Goal 3: Mental Health and Well-Being
}

\author{
Emily Faulks ${ }^{1}$, Janniry Belen ${ }^{2}$, Andres Sweetland ${ }^{3}$ \\ ${ }^{1}$ Colorado College, ${ }^{2}$ Moravian College, ${ }^{3}$ Colorado State University
}

The United Nations Member States created Sustainable Development Goals and they urge international leadership to commit to 17 goals that are aimed towards increasing peace and prosperity across the globe. These goals are all unique but inextricably linked to social and environmental inequality. Sustainable Development Goal 3 aims to "ensure healthy lives and promote well-being for all at all ages (United Nations)." Our research consists of three unique targets that function as touchstones to achieve this goal: healthcare, traffic safety, and mental health.

SDG Theme: SDG 3 - Good Health \& Wellbeing

Type: Story map

\section{The Power of Quality Education}

\author{
Melissa Morales ${ }^{1}$, Maria Fernanda Ridoutt ${ }^{2}$, Alec Buttner ${ }^{1}$, Bryn Bernier ${ }^{1}$, Eila Sullivan ${ }^{3}$, \\ Matthew Viozzi ${ }^{3}$, Hannah Masling ${ }^{3}$ \\ ${ }^{1}$ Moravian College, ${ }^{2}$ Universidad Nacional Agraria La Molina, ${ }^{2}$ Colorado College
}

The SDG 4 presenters focus on target 4.1 using a Talanoa Dialogue. This dialogue was held by a few teachers and students from across America, and they discussed where we are in education as a nation. The presenters use the Talanoa Dialogue to discuss how America's education system can progress and what are the crucial steps to attain equitable and quality education for all.

SDG Theme: SDG 4 - Quality Education

Type: Prezi 


\title{
Clean Water
}

\author{
Jessica O'Reilly ${ }^{1}$, Kenna Malott ${ }^{1}$ \\ ${ }^{1}$ Indiana University
}

My research will be conducted to find ways to sanitize and supply water everywhere, but especially in the places that are the most impacted by contaminated water. The research will address the processes needed to collect and sanitize water, as well as distribute it. The goal is to be able to implement clean water filling stations around the local town of Bloomington Indiana, and eventually implement the filling stations around the world.

SDG Theme: SDG 6 - Clean Water \& Sanitation

Type: E-poster

\section{SDG 2 - Zero Hunger; Case Study: UN World Food Programme (WFP)}

\author{
Sarah Bredy ${ }^{1}$, Rebecca Horetsky ${ }^{1}$, Becky Petrou O’Rourke ${ }^{1}$, Jamie Poirier ${ }^{1}$, Ashley Roes ${ }^{1}$, and \\ Rachel Xue ${ }^{1}$ \\ ${ }^{1}$ Boston University
}

The United Nations World Food Programme has a long history of commitment to meeting the objectives of SDG Goal 2. This presentation will focus on this organization's objectives, accomplishments, and progress in working towards creating a world where no one suffers from food insecurity.

SDG Theme: SDG 2 - Zero Hunger

Type: Short talk 


\title{
Oaxaca \& Climate Change: Preserving the Environment \& Indigenous, Medicinal Knowledge
}

\author{
Annayelli Pacheco ${ }^{1}$ \\ ${ }^{1}$ Indiana University
}

Climate change is declining the agency of indigenous communities. The indigenous peoples of Oaxaca hold cultural, traditional knowledge which is an important element of indigenous medical systems in Mexico. Oaxaca is facing drought and forest fires alongside growing infestations of the forests within the Sierra Juarez mountain range. These ongoing climate events impact the livelihoods of these indigenous groups that make up a portion of the Oaxacan population. The deterioration of natural resources impacts the use of indigenous medical systems as well as the transmission of knowledge found within these systems.

SDG Theme: SDG 3 - Good Health \& Wellbeing, SDG 10 - Reduced Inequalities

Type: Short talk 


\section{Session 1B. Affordable \& Clean Energy and Industry, Innovation \& Infrastructure (SDGs 7, 9)}
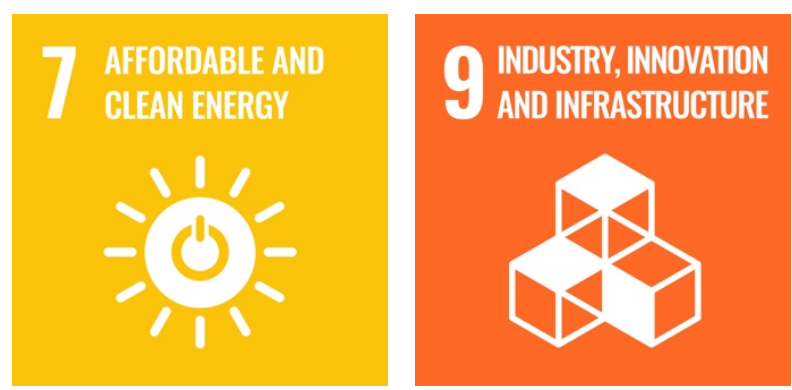


\title{
The United States' Renewable Energy Utilization
}

\author{
Lucy Mellen $^{1}$ \\ ${ }^{1}$ Indiana University
}

I will be assessing the United States' use of renewable energy in comparison to that of top renewable energy using countries. This analysis will explore the solar energy potential of North African countries such as Morocco, Tunisia, Algeria, and Egypt as well as other countries like Sweden, one of the top energy consumers in the world that utilizes over half of its energy from renewables.

SDG Theme: SDG 7 - Affordable and Clean Energy

Type: E-poster

\section{Internet Expansion Plan Proposal in Developing Countries: Peru as a Case Study}

${ }^{1}$ Garion Johnson, ${ }^{2}$ Gonzalo Jose Manuel Neira Chacate, ${ }^{3}$ Paul Levasseur, ${ }^{3}$ Andrew Goodolf, and ${ }^{4}$ Ally Murphy Pauletto

${ }^{1}$ Michigan Technological University, ${ }^{2}$ Universidad Nacional Agraria La Molina, ${ }^{3}$ Moravian College, ${ }^{4}$ Colorado State University

The presentation will explore how cell phone carriers have helped countries work toward SDG 9, Target 9.c. It will be a critical perspective and will include economic, social, and political implications in the countries researched.

SDG Theme: SDG 9 - Industry, Innovation, \& Infrastructure

Type: E-poster 


\title{
Glitter in make up as microplastics: comparative life cycle analysis of biodegradable and plastic glitter
}

\author{
Iuliia Tcibulnikova ${ }^{1}$ \\ ${ }^{1}$ Michigan Technological University
}

My project is about life cycle analysis (LCA) and comparison of make-up products with synthetic plastic glitter and biodegradable glitter made from eucalyptus cellulose (environmental impacts and market incentives).

SDG Theme: SDG 9 - Industry, Innovation, \& Infrastructure

Type: Short talks

\section{Internet Instability: The risks posed by climate change}

\author{
Luke Huels ${ }^{1}$ \\ ${ }^{1}$ Monash University
}

This presentation will explore Australia's internet infrastructure vulnerability to climate change, chiefly to sea-level rise/storm surge and from wildfires. This is an under investigated topic in the Australasian region (and, arguably, internationally); the current research forms a baseline from existing knowledge and provides direction for future research and management actions.

SDG Theme: SDG 8 - Decent Work \& Economic Growth, SDG 9 - Industry, Innovation, \& Infrastructure, SDG 10 - Reduced Inequalities, SDG 11 - Sustainable Cities \& Communities

Type: Short talk 


\section{Session 1C. Reduced Inequalities and Gender Equality (SDGs 2, 5, 10)}
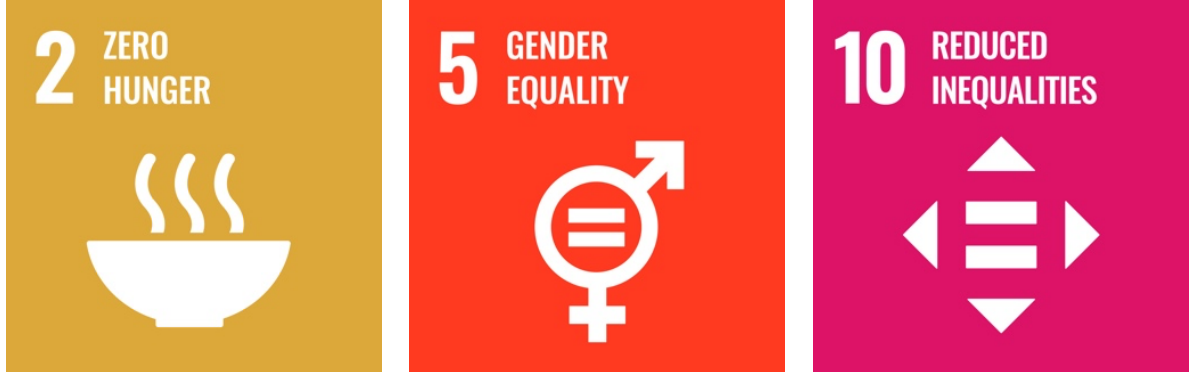


\title{
Americans For Tax Fairness and Reducing Inequalities
}

\author{
Maxine Slattery ${ }^{1}$, Eden Floyd $^{1}$, Vyshnavi Kosuri ${ }^{1}$, Christine Liao $^{1}$, Maia Adley ${ }^{1}$ \\ ${ }^{1}$ Boston University
}

We examined how Americans for Tax Fairness works toward Sustainable Development Goal 10: Reduced Inequalities. We also looked at the organization's objectives and its strategies for accomplishing those objectives.

SDG Theme: SDG 10 - Reduced Inequalities

Type: Short talk

\section{Climate Change and Corn: The threat to Mexican Livelihoods}

\author{
Jessica McClintock-Ortiz ${ }^{1}$ \\ ${ }^{1}$ Indiana University
}

As a result of anthropogenic climate change, a staple of Mexican diet, culture and agriculture is at stake: maize. México is predicted to be a region at risk from climate change, comparative to other regions globally, and as a result small-scale farming and agriculture are expected to be in danger. Where do vulnerabilities intersect, what are the solutions being implemented, what are the weaknesses of these solutions and how can future solutions target critical areas of need?

SDG Theme: SDG 2 - Zero Hunger, SDG 10 - Reduced Inequalities

Type: E-poster 


\title{
Urban Green Spaces and Sustainability
}

Elyse Goin ${ }^{1}$, Allison Ludlow ${ }^{2}$, Shauna Devoy ${ }^{3}$, Rodney Berger ${ }^{2}$, Cassie Allson ${ }^{3}$, Chenwei Zhu ${ }^{4}$

${ }^{1}$ Scripps Institute of Oceanography, ${ }^{2}$ Moravian College, ${ }^{3}$ University of Derby, ${ }^{4}$ Colorado State University

This presentation will be an analysis of SDG 11 - Sustainable Cities and Communities and the target 7, which is aims to provide access to safe and accessible green spaces. We will introduce two case studies about green spaces.

SDG Theme: SDG 11 - Sustainable Cities \& Communities

Type: E-poster

\section{The Intersectionality of Environmental and Societal Well-Being in Reducing Inequalities}

\author{
Sydney Johnson ${ }^{1}$ \\ ${ }^{1}$ Indiana University
}

I will investigate the Kingdom of Bhutan, and compare/contrast the country's environmental and economic policies with those of the United States. Specifically, I want to focus on Bhutan's unique approach to development, Gross National Happiness (GNH), and how GNH may promote the implementation of policies that encourage democracy and focus on combating social and environmental injustices. A research question I will explore is: How can a shift from measuring the well-being of the economy to measuring the well-being of the people shape future government and economic policies?

SDG Theme: SDG 10 - Reduced Inequalities

Type: E-poster 


\section{Session 1D. Climate Action (SDG 13)}

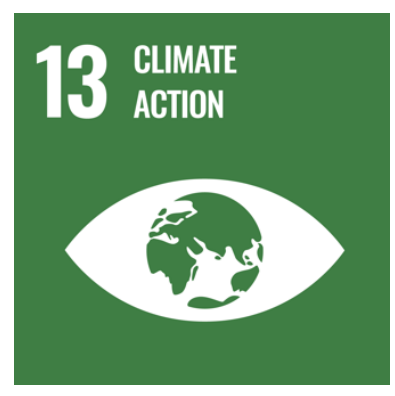




\title{
Climate Action Plans for Universities in the YEAH! Network
}

Christopher Dorich ${ }^{1}$, Cherrie Donoghue ${ }^{2}$, Megan Farish $^{2}$, Rachel Cox ${ }^{2}$, Ellie Orme ${ }^{2}$, Kathiana Aznaran $^{3}$, Ursala Fiorela Navarro Abarca ${ }^{3}$, Taylor Sanders ${ }^{4}$, Matthew Woods ${ }^{2}$, Macey Halgren ${ }^{5}$

${ }^{1}$ Colorado State University, ${ }^{2}$ University of Derby, ${ }^{3}$ Universidad Nacional Agraria La Molina, ${ }^{4}$ Moravian College, ${ }^{5}$ Indiana University

Our presentation is based on SDG 13.3. We will assess the Climate Action Plans of each of our universities, and make a proposal if one has not been established. We will be looking to see how transparent each institution is with their progress, or lack thereof, and make comparisons.

SDG Theme: SDG 13 - Climate Action

Type: Pre-recorded Google Slides

\section{Traditional Ecological Knowledge and Environmental Policy in Southeast Alaska}

\author{
Ben Bridges $^{1}$ \\ ${ }^{1}$ Indiana University
}

Traditional ecological knowledge (TEK), a concept encapsulating non-Western epistemologies related to the environment, has entered into political, academic, and activist lexicons in recent decades. This poster explores TEK in environmentally focused policies and statements in Southeast Alaska, noting the distinctions between the ways in which different parties invoke the term.

SDG Theme: SDG 13 - Climate Action

Type: E-poster 


\title{
Green Imperialism in French Polynesia
}

\author{
Sara Mills ${ }^{1}$ \\ ${ }^{1}$ Indiana University
}

French Polynesia is currently still partially under French control. As French Polynesia is a SIDS, they are facing extreme weather events and sea level rise. French resource extraction and a nuclear test site have degraded their environment. I will examine the environmental justice components of this situation in relation to eco-governance and development projects.

SDG Theme: SDG 13 - Climate Action

Type: E-poster

\section{Preparing for the Inevitable Low-Carbon Economy: Current Actions of the United States of America, Saudi Arabia, and the Russian Federation}

\author{
Beverley Thompson ${ }^{1}$ \\ ${ }^{1}$ Indiana University
}

I will be conducting an E-Poster presentation on my semester project for Indiana University class Negotiating Climate (INTL-I420). My research question is how the United States, Saudi Arabia, and the Russian Federation are preparing for the low-carbon transition and the climate crisis?

SDG Theme: SDG 13 - Climate Action

Type: E-poster 


\title{
The Power of Film in the Climate Crisis
}

\author{
Meloddy $\mathrm{Gao}^{1}$ \\ ${ }^{1}$ Indiana University
}

Films on climate change and environmental topics have been incorporated into community environmental education efforts. Individuals are able to get exposure to climate issues and available solutions through film. Using a sociological lens, individual perceptions of environmental films and actions following the viewing of such films are analyzed to gain a better understanding of how cinematic storytelling impacts climate action.

SDG Theme: SDG 13 - Climate Action

Type: Short talk 


\section{Session 1E. Peace, Justice, \& Strong Institutions and Partnerships for the Goals (SDGs 13, 16, 17)}
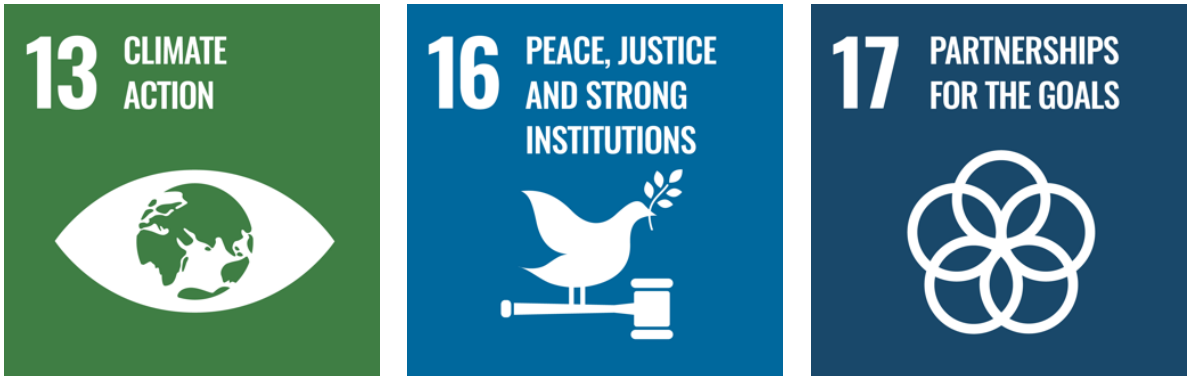


\title{
Institutionalization of Climate Finance in the Green Climate Fund
}

\author{
Leo Banks ${ }^{1}$ \\ ${ }^{1}$ Indiana University
}

I will investigate the institutionalization of climate finance as represented by the Green Climate Fund. I will discuss not only the practices of the GCF as the institutionalization of climate finance but also the challenges and opportunities that these practices create and how they contribute to worldwide notions of climate governance.

SDG Theme: SDG 16 - Peace, Justice, \& Strong Institutions

Type: E-poster

\section{Disparate Impacts of Climate Change on Indigenous Communities in the Arctic Region}

\author{
Ariana Katz ${ }^{1}$ \\ ${ }^{1}$ Indiana University
}

In this project, I will study the topic of climate justice and the ways that Indigenous communities in the Arctic region are facing some of the most extreme consequences of climate change, yet are often left out of policy, decision-making and important conversations that heavily impact their communities.

SDG Theme: SDG 16 - Peace, Justice, \& Strong Institutions

Type: E-poster 


\title{
Timeline of Uluru- Kata Tjuta
}

\author{
Mary Gerrity ${ }^{1}$, Chris McCormick ${ }^{1}$, Nana Ueno ${ }^{1}$, Wuillian Pineda ${ }^{1}$ \\ ${ }^{1}$ Colorado State University
}

This presentation will give a timeline of the Uluru- Kata Tjuta National park and the area around it. The poster will focused on the aboriginal people, early european settlers, the rise in tourism in the 1950 's, the struggle for land rites in the 1970's and 1980's, and the state of the area today.

SDG Theme: SDG 16 - Peace, Justice, \& Strong Institutions

Type: Storyline using adobe software

\section{Future Pathways for Action for Climate Empowerment (ACE)}

\author{
Alessandro Caprini ${ }^{1}$; Aneeqah Tariq ${ }^{1}$; Cecilia Consalvo ${ }^{1}$; Max van Deursen ${ }^{1}$; Sofie de Wit ${ }^{1}$ \\ ${ }^{1}$ Wageningen University
}

Action for Climate Empowerment (ACE) refers to Article 6 of the UNFCCC and Article 12 of the Paris Agreement. It calls for public participation, awareness, and education. Through a discursive institutionalist lens, we provide an explanation for the lack of implementation. Our work links to ACE negotiations at COP26.

SDG Theme: SDG 13 - Climate Action

Type: Short talk 


\title{
Police Brutality and State Violence: A Global Phenomenon
}

\author{
Casmali Lopez ${ }^{1}$, Veena Namboodri ${ }^{2}$, Emily Mehlhop ${ }^{3}$, Trevor Cunningham ${ }^{4}$, Albaraa Mesawi ${ }^{4}$ \\ ${ }^{1}$ Colorado College, ${ }^{2}$ Michigan Technological University, ${ }^{3}$ Colorado State University, ${ }^{4}$ Moravian \\ College
}

\begin{abstract}
A target of SDG 16 (Peace, Justice, and Strong Institutions) is to reduce all forms of violence. Our project explores the current state of this target as it relates to police brutality by identifying global case studies of this form of state violence.
\end{abstract}

SDG Theme: SDG 16 - Peace, Justice, \& Strong Institutions

Type: Story Map 


\section{Session 2A. Interdisciplinary SDG topics (SDG nexus spaces)}

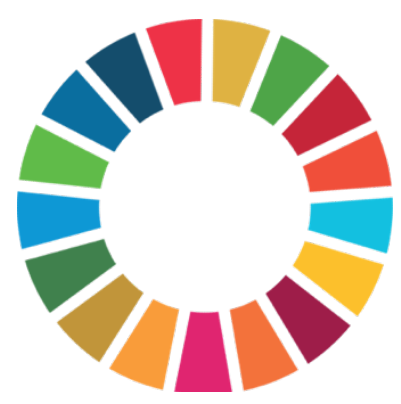




\title{
Early Career Scientists Sailing with SDGs to Antarctica
}

\author{
Clément Astruc-Delor ${ }^{1}$, Margot Legal - Baptiste Arnaud ${ }^{1}$, Niels Dutrievoz ${ }^{1}$, Lana Lenourry ${ }^{1}$, \\ Olivier Smith ${ }^{1}$ \\ ${ }^{1}$ École Normale Supérieure
}

We're presenting a sailing adventure: an 8-month scientific research expedition, leaving from France towards the Antarctic peninsula with 6 graduate students - from different fields - on board that will investigate the effects of climate change and human activities on the studied ecosystems. Classes will be involved and empowerment of the wide audience is scheduled. Jump on-board!

SDG Theme: SDG 4 - Quality Education, SDG 9 - Industry, Innovation, \& Infrastructure, SDG 12 - Responsible Consumption \& Production, SDG 13 - Climate Action, SDG 14 - Life Below Water, SDG 17 - Partnerships for the Goals

Type: Press Conference

\section{The Kankyo Café method of environmental dialogue and SDGs}

\author{
Jin Tanaka ${ }^{1}$ and Mituru Tada ${ }^{1}$ \\ ${ }^{1}$ Kyushu University
}

The 2030 Agenda for Sustainable Development states the need for regional-level dialogue. Scientists and the public have been engaging in dialogues, known as "Kankyo [environment] Cafés." The café is an event at which an environmental dialogue takes place with the aim of deepening understanding and promoting empathy.

SDG Theme: SDG 4 - Quality Education, SDG 11 - Sustainable Cities \& Communities, SDG 12 - Responsible Consumption \& Production, SDG 13 - Climate Action, SDG 17 - Partnerships for the Goals

Type: Short talk 


\title{
Cerro Azul Meambar
}

\author{
Joe Burke ${ }^{1}$, Gabby Hagewiesche ${ }^{1}$, and Kylie Rude ${ }^{1}$ \\ ${ }^{1}$ Colorado State University
}

We will be discussing the National Park Cerro Azul Meambar. We will be focusing on general information on the park and how the park helps contribute to conservation efforts and human/animal rights.

SDG Theme: SDG 5 - Gender Equality, SDG 10 - Reduced Inequalities, SDG 15 - Life on Land Type: Prezi

\section{Talanoa Dialogues on the SDGs}

\author{
Jake Arculli ${ }^{1}$, Sean Dunbar ${ }^{1}$, Lucia Daranyi ${ }^{1}$, Emily Faulks ${ }^{1}$, Zach Ginn ${ }^{1}$, Casmali Lopez ${ }^{1}$, \\ Victoria Rosa ${ }^{1}$, Adel Salih ${ }^{1}$, Carmen Villalba ${ }^{1}$ \\ ${ }^{1}$ Colorado College
}

Talanoa Dialogues borrow from a Fijian conflict resolution process, and were instituted as part of the COP24 climate negotiations in 2017. Our YEAH teams convened small interpersonal dialogues related to SDGs and specific targets; here, we'll feature SDGs/targets \#12 (Responsible Consumption \& Production), \#14/15 (Life on Land/Below Water; healthy coastlines; and \#17 (violence reduction and police brutality).

SDG Theme: SDG 10 - Reduced Inequalities, SDG 12 - Responsible Consumption \& Production, SDG 14 - Life Below Water, SDG 15 - Life on Land, SDG 16 - Peace, Justice, \& Strong Institutions

Type: Press Conference 


\title{
The Effects of Palm Oil on the Habitats, Biodiversity, and Environment of Populations in Indonesia and Southeast Asia
}

\author{
Eric Salzeider ${ }^{1}$ \\ ${ }^{1}$ Indiana University
}

The Palm Oil Industry has devastated the biodiversity, habitats, and environments of Indonesia and neighboring countries. Deforestation, plantation emissions, and unsustainable agricultural practices drive climate change in the region. I aim to describe the habitat loss, biodiversity loss, species and indigenous populations affected, and adverse effects on climate change to educate those on the consequences of palm oil.

SDG Theme: SDG 12 - Responsible Consumption \& Production

Type: E-Poster 


\section{Session 2B. Industry, Innovation \& Infrastructure and Sustainable Cities \& Communities (SDGs 9, 11)}
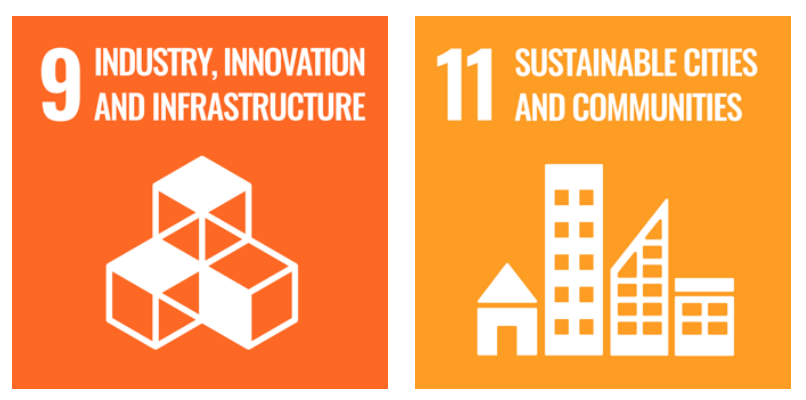


\title{
Ngorongoro Conservation Area \& the Maasai
}

\author{
Tori Applehans ${ }^{1}$, Marissa Lopez ${ }^{1}$, Ethan Wagenseller ${ }^{1}$, Stojan Hansen ${ }^{1}$ \\ ${ }^{1}$ Colorado State University
}

Our presentation will highlight the Ngorongoro Conservation Area located in Northern Tanzania from the perspective of the Maasai, a semi-nomadic pastoral people who raise livestock alongside wildlife (inside and outside of the park).

SDG Theme: SDG 11 - Sustainable Cities \& Communities, SDG 16 - Peace, Justice, \& Strong Institutions, SDG 17 - Partnerships for the Goals

Type: A prezi narrated presentation

\section{The Influence of Urban Planning on Sustainable Lifestyles}

\author{
Lauren Wisniewski ${ }^{1}$ \\ ${ }^{1}$ Indiana University
}

In my work I compare the city planning of Beijing, China and Masdar, United Arab Emirates. Masdar is a zero emissions city of the future, which has attained its green certifications due to careful, environmentally conscious planning. On the other hand, Beijing was planned for rapid growth, which has created an industrial atmosphere that relies on fossil fuels.

SDG Theme: SDG 11 - Sustainable Cities \& Communities

Type: E-poster 


\title{
Smart Cities Council: Creating an Impact Through SDG 11
}

Keeley Bombard ${ }^{1}$, Abigail Kahn ${ }^{1}$, Ashley Pung ${ }^{1}$, Matthew Folan ${ }^{1}$, Rebecca Hyatt ${ }^{1}$, and Xingpei Zhang ${ }^{1}$

${ }^{1}$ Boston University

This presentation was created as a group project for my Biology of Global Change course at Boston University, where we were tasked with finding an organization that exemplified the SDG that we were assigned to. My group focused on the Smart Cities Council, a non-governmental organization that coincides with SDG 11, sustainable cities and communities.

SDG Theme: SDG 11 - Sustainable Cities \& Communities

Type: Short talk

\section{Pump Underground Storage Hydro (PUSH)}

\author{
Shardul Tiwari ${ }^{1}$ \\ ${ }^{1}$ Michigan Technological University
}

Pumped underground hydro storage (PUSH) works on the same principle as hydropower plants. We use excess electricity in the grid, during the night hours when wind power plants are generating and we use the cheap electricity to pump water from the lower underground reservoir to pump water in the upper underground reservoir. During the day when we need more electricity, we use water in the reservoir to flow due to gravity and generate electricity. We develop such a facility in abandoned underground mines in Michigan.

SDG Theme: SDG 7 - Affordable and Clean Energy

Type: E-poster 


\title{
Community Participation and Sustainable Livelihoods: A Case Study of Hiware Bazar (India)
}

\author{
Shilpy Arora ${ }^{1}$ \\ ${ }^{1}$ Massey University
}

The study highlights the success story of Hiware Bazar, a village in India. From a poor, droughtprone and water-scarce settlement, the village transformed into an economically strong and environmentally sustainable community within a decade. The community participation in governance and management of resources led to sustainable development in the village.

SDG Theme: SDG 11 - Sustainable Cities \& Communities, SDG 12 - Responsible Consumption \& Production, Sustainable Livelihoods

Type: Press Conference 


\section{Session 2C. Responsible Consumption and Production (SDG 12)}

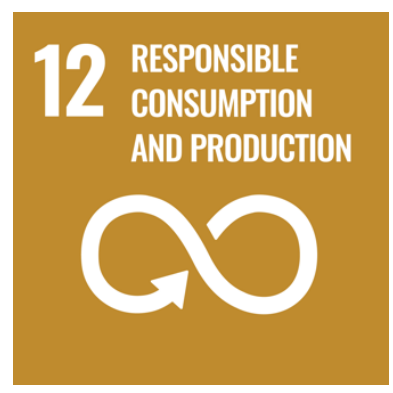




\title{
The Relationship Between Producer Transparency and Sustainable Consumption
}

\author{
Daniella Calvimontes ${ }^{1}$, Zofia Frieberg ${ }^{2}$, Mazey Hall ${ }^{3}$, Victoria Rosa ${ }^{4}$, Carmen Villalba ${ }^{4}$, \\ Christopher Wilson ${ }^{5}$, Jack Kirby ${ }^{3}$ \\ ${ }^{1}$ Universidad Nacional Agraria La Molina, ${ }^{2}$ Michigan Technological Univesity, ${ }^{3}$ University of \\ Derby, ${ }^{4}$ Colorado College, ${ }^{5}$ Moravian College
}

Our project will describe practices of information transparency in food-producing entities using case-studies on randomly selected subjects from around the globe. Objectionable and commendable practices will be shared with a population of potential consumers to explore how such information dictates their choice of commercial food materials.

SDG Theme: SDG 12 - Responsible Consumption \& Production

Type: Pre-recorded Talk

\section{Case Studies of Eco-Tourism in Tunisia}

\author{
Anna Wysocki ${ }^{1}$, Joy Pereira ${ }^{1}$, Katie Greene ${ }^{1}$, Emma Perme $^{1}$, Josh Yamada ${ }^{1}$, Patlapa \\ Sompolpong ${ }^{1}$ \\ ${ }^{1}$ Boston University
}

Our presentation is a general overview of SDG 12 followed by a case study on Dar Zaghouan, the first eco-tourism farm in Tunisia. We touch on strategies and objectives of both Dar Zaghouan and SDG 12, and cover successes of the organization.

SDG Theme: SDG 12 - Responsible Consumption \& Production

Type: Recorded video 


\title{
A Comparative Analysis of China and Indonesia's Adaptation Techniques for Rice Production
}

\author{
Marria Peduto ${ }^{1}$ \\ ${ }^{1}$ Indiana University
}

Rice production is expected to decrease in the next century as a result of climate change. I will analyze the adaptive response of two countries, China and Indonesia, and compare these practices to understand the different ways countries can approach adaptation in agricultural production.

SDG Theme: SDG 12 - Responsible Consumption \& Production

Type: E-poster

\section{Shade Grown Coffee In Costa Rica}

\author{
Jenna Lentz ${ }^{1}$ \\ ${ }^{1}$ Indiana University
}

This presentation will focus on the role of Agriculture in Costa Rica, specifically the coffee industry. Traditional methods of growing coffee used shade, but as the popularity of coffee grew so did the need to increase production. This led to industrialized, sun-grown plantations that are harming the earth and contributing to climate change.

SDG Theme: SDG 12 - Responsible Consumption \& Production

Type: E-poster 


\title{
Agrivoltaics: Exploring the Opportunities \& Barriers to Combined Solar and Agriculture Systems
}

\author{
Alexis S. Pascaris ${ }^{1}$ \\ ${ }^{1}$ Michigan Technological University
}

Agrivoltaics, the strategic co-development of land for both solar energy production and agriculture, can meet growing demands for energy and food simultaneously while reducing fossil fuel consumption. This project explores the socio-political barriers to agrivoltaic development while also considering the potential environmental impacts of such systems using Life Cycle Assessment.

SDG Theme: SDG 12 - Responsible Consumption \& Production

Type: Short talk 


\section{Session 2D. Climate Action and Good Health \& Wellbeing (SDGs 3, 13)}
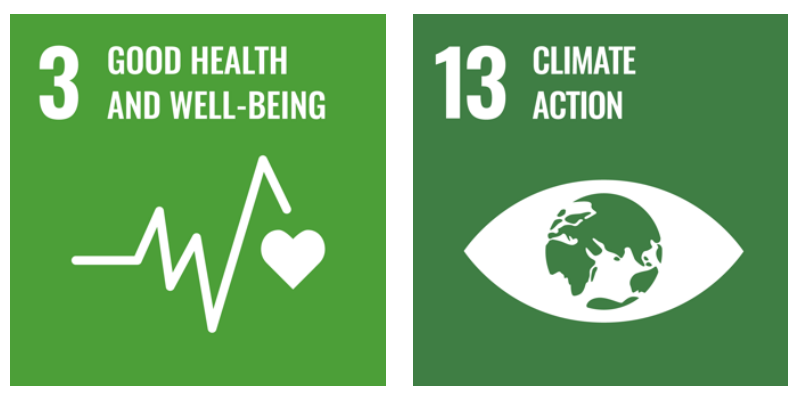


\title{
Local ocean conservation- a Kenyan marine-life NGO
}

\author{
Aman Patel ${ }^{1}$ \\ ${ }^{1}$ Boston University
}

This presentation will introduce Local Ocean Conservation, an NGO in my home country that is doing amazing work to care for marine ecosystems and biota.

SDG Theme: SDG 13 - Climate Action, SDG 14 - Life Below Water, SDG 15 - Life on Land

Type: Short talk

\section{Climate Change and Jamaican Agriculture: Addressing Impacts on Small-Scale Farmers}

\author{
Margaret VanSchaik ${ }^{1}$ \\ ${ }^{1}$ Indiana University
}

I will be discussing how climate change is affecting Jamaica's agricultural sector and specifically the impacts of climate change on small-scale farmers in the country. I will talk about the implications of climate change impacts for the livelihoods and specifically food security of small-scale farmers.

SDG Theme: SDG 13 - Climate Action

Type: E-poster 


\title{
Hauscarán National Park: Chavin Culture Through the Lens of Traditional Artwork
}

\author{
Serena Natonabah ${ }^{1}$, Marti Zolnir ${ }^{1}$, Tracey Malter ${ }^{1}$ \\ ${ }^{1}$ Colorado State University
}

Hauscarán National Park is located on land once known as the Chavín de Hauntar, a cultural site for the Chavin people. This Storymap will take a look at Chavin culture through the lens of traditional artwork and its connection to the land within the park.

SDG Theme: SDG 13 - Climate Action

Type: Story Map

\section{Experience of Application of SDGs from Theory to Practice}

\author{
Tracey Hale ${ }^{1}$ \\ ${ }^{1}$ Massey University
}

I will be presenting my experience of working towards completing a Masters in Sustainable Development Goals at Massey University in New Zealand. It enabled me to prepare for a change in career path from accounting towards environmental sustainability through real-life applications from case studies to practicum-based approaches.

SDG Theme: SDG 3 - Good Health \& Wellbeing, SDG 13 - Climate Action

Type: Short talk 


\title{
India's current heatwave and flooding crisis
}

\author{
Chinmayee Sakhare ${ }^{1}$ \\ ${ }^{1}$ Indiana University
}

I will be presenting on behalf of Indiana University on India's climate crisis and how they are facing an increasing number of heatwaves and floods.

SDG Theme: SDG 3 - Good Health \& Wellbeing, SDG 13 - Climate Action

Type: E-poster 


\section{Session 2E. Life Below Water and Life on Land (SDGs 14, 15)}
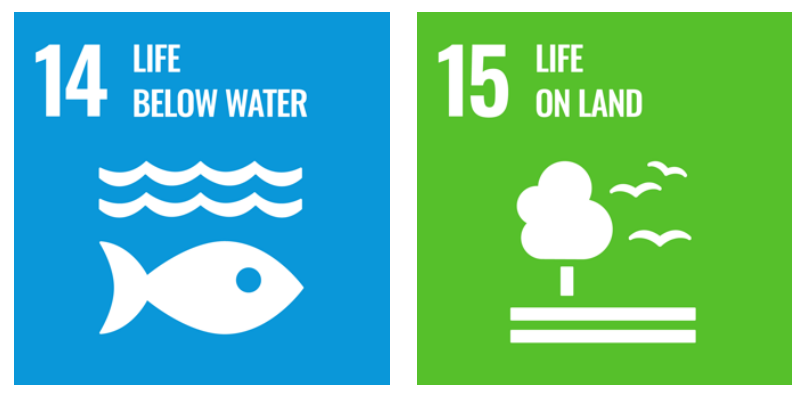


\title{
Effects of Deforestation on Marine Ecosystems and Biodiversity: Case Studies from the United States, Peru and the United Kingdom
}

\author{
Emma Conrad-Rooney ${ }^{1}$, Zach Ginn ${ }^{2}$, Chelsea Hill ${ }^{7}$, Anna Kurkierewicz ${ }^{4}$, Abby Mikolitis ${ }^{5}$, \\ Karina Calizaya Torre ${ }^{6}$, Barbara Grados Vargas ${ }^{6}$, Paula López Vargas ${ }^{6}$, Sharon Vizcarra ${ }^{6}$, Ziqi \\ $\mathrm{Wu}^{3}$, and Connor Zamora ${ }^{7}$ \\ ${ }^{1}$ Boston University, ${ }^{2}$ Colorado College, ${ }^{3}$ Colorado State University, ${ }^{4}$ University of Derby, \\ ${ }^{5}$ Michigan Technological University, ${ }^{6}$ Universidad Nacional Agraria La Molina, ${ }^{7}$ Moravian \\ College
}

Deforestation has many unintended consequences on marine and aquatic life ranging from nutrient pollution to rising coastal temperatures. In addition to integrating the study of SDG 14 Life Below Water and SDG 15 - Life on Land, our research group will highlight our range of geographical diversity, by focusing on case studies from Peru, the United States, and the United Kingdom.

SDG Theme: SDG 14 - Life Below Water, SDG 15 - Life on Land

Type: Pre-recorded Google Slides

\section{SIDS \& Changing Lands}

\author{
Amy Zhou ${ }^{1}$ \\ ${ }^{1}$ Indiana University
}

This research proposal will explore small islands developing states and the impacts of climate change on their economy, agriculture, sociopolitical environment, and overall health.

Specifically, it will analyze the nations of The Bahamas and The Maldives and how they have handled their situations.

SDG Theme: SDG 15 - Life on Land

Type: E-poster 


\title{
Bialowieza Forest
}

\author{
Matthew Laffey ${ }^{1}$, Victoria Oliu ${ }^{1}$, McKenleigh Spitler ${ }^{1}$ \\ ${ }^{1}$ Colorado State University
}

This poster presentation will be about the culture and history within the Bialoweiza Forest in Poland.

SDG Theme: SDG 15 - Life on Land

Type: E-poster

\section{Khao Sok National Park}

\author{
Elizabeth Madura $^{1}$, Ally Bormann $^{1}$, Claire Silvestre $^{1}$ \\ ${ }^{1}$ Colorado State University
}

We plan to present the history and connection to SDG's in relevance to Khao Sok National Park in Thailand. We will discuss how the park was created and why it is important to discuss and what the park now is like.

SDG Theme: SDG 15 - Life on Land, SDG 17 - Partnerships for the Goals

Type: Other presentation 


\title{
Arenal Volcano National Park in Costa Rica
}

\author{
Allison Uri ${ }^{1}$, Dasha Petrova ${ }^{1}$, Alex Burks $^{1}$ \\ ${ }^{1}$ Colorado State University
}

Our presentation will be about the intersections of places \& people in Costa Rica and how they impact the process of management for Arenal Volcano National Park. We will share the unique aspects about the country such as their perspective on biodiversity, Indigenous culture, and issues with environmental damage.

SDG Theme: SDG 15 - Life on Land

Type: E-poster 